\title{
Migraine attacks during menses: efficacy of eletriptan and relationship to recurrence after response
}

\author{
Almas Bhambri", Chatterjee Abdulsattar \\ From The European Headache and Migraine Trust International Congress \\ London, UK. 20-23 September 2012
}

\section{Introduction}

Compared with migraine attacks not related to menses, migraine attacks during menstruation have been shown to have longer duration and higher recurrence rates, are more resistant to treatment, and are associated with greater functional disability.

\section{Objective}

To compare migraine attacks during menses to other migraine attacks and assess recurrence of migraine after response in both these groups.

\section{Design/methods}

Data for eletriptan $20 \mathrm{mg}(\mathrm{E} 20), 40 \mathrm{mg}(\mathrm{E} 40), 80 \mathrm{mg}(\mathrm{E} 80)$ were pooled from 5 similarly designed RCT's of eletriptan. Women with migraine beginning within 1 to 4 days of menstrual flow $(\mathrm{Gl})$ were compared to women with migraine not associated with menses (G2). Headache response within 2 hours to Eletriptan and placebo was compared in women within Gl and G2 using logistic regression analyses controlling for baseline headache severity, treatment group(E20, E40, E80, Pbo) and study. Recurrence of migraine after initial response within 2 hours and up to 24 hours post-headache was compared between $\mathrm{Gl}$ and $\mathrm{G} 2$ also using logistic regression. Adverse event frequencies were also compared between groups.

\section{Results}

Five studies $(\mathrm{N}=3217)$ were included in this analysis. $2796(86.9 \%)$ of the subjects were women. Mean age for Gl $(\mathrm{N}=630)$ was $36.8(50=8.1)$ and $\mathrm{G} 2(\mathrm{~N}=1586)$ was $37.7(50=9.9)$ years. Headache response within 2 hours was superior in the Eletriptan treated groups vs. placebo in $\mathrm{Gl}(\mathrm{E} 20$ : $\mathrm{OR}=3.8,95 \% \mathrm{CI}=1.8,7.7 ; \mathrm{p}<0.0002)(\mathrm{E} 40$ : $\mathrm{OR}=5.3,95 \% \mathrm{CI}=3.3,8.7 ; \mathrm{p}<0.0001)(\mathrm{E} 80: \mathrm{OR}=6.5,95 \%$ $\mathrm{CI}=3.8,11.05 ; \mathrm{p}<0.0001)$ and in $\mathrm{G} 2(\mathrm{E} 20: \mathrm{OR}=1.65,95 \%$ $\mathrm{CI}=1.01,2.7 ; \mathrm{p}<0.045)(\mathrm{E} 40: \mathrm{OR}=2.9,95 \% \mathrm{CI}=2.2,3.9$; $\mathrm{p}<0.0001)(\mathrm{E} 80: \mathrm{OR}=4.2,95 \% \mathrm{CI}=3.1,5.8 ; \mathrm{p}<0.0001)$. Headache recurrence rates were higher in $\mathrm{Gl}$ compared to $\mathrm{G} 2(\mathrm{OR}=1.66,95 \% \mathrm{CI}=1.22,2.26 ; \mathrm{p}<0.001)$. Adverse events were comparable between $\mathrm{Gl}$ and $\mathrm{G} 2$.

\section{Conclusions}

Eletriptan has similar efficacy in the treatment of migraines occurring within and without a menstrual period. Migraine attacks during menses have higher odds of recurrence than migraines occurring at other times. Eletriptan was safe and well tolerated.

\section{Acknowledgements}

Study supported by Pfizer. Available upon request. (Complete list exceeds character limit)

Published: 21 February 2013

doi:10.1186/1129-2377-14-S1-P196

Cite this article as: Bhambri and Abdulsattar: Migraine attacks during menses: efficacy of eletriptan and relationship to recurrence after response. The Journal of Headache and Pain 2013 14(Suppl 1):P196. 